\title{
Axiomatic Design in Obtaining a Device for Ultrasonic Machining
}

\author{
Oana Dodun ${ }^{1, *}$,Ema Panaite $^{2}$, Petru Duşa ${ }^{1}$, Gheorghe Nagît ${ }^{1}$, Margareta Coteaţă ${ }^{1}$ and Laurențiu Slătineanu ${ }^{1}$ \\ 1"Gheorghe Asachi" Technical University of Iaşi, Department of Machine Manufacturing Technology, Blvd. D. Mangeron, \\ 59A, 700050 Iaşi, România \\ 2"Gheorghe Asachi" Technical University of Iaşi, Department of Mechanical Engineering and Road Automotive \\ Engineering, Blvd. D. Mangeron, 43, 700050 Iaşi, România
}

\begin{abstract}
Ultrasonic abrasive cavitational machining is a nonconventional machining method applied to remove surfaces in workpieces made of brittle, hard, or non-conductive materials that cannot be efficiently machined by other classical or nonconventional machining methods. Among the factors that can affect the values of the parameters of technological interest for the ultrasonic machining process, the relative pressure between the ultrasonic tool and the workpiece surface to be machined could be considered. The main objective of the research presented in this paper was to analyze the possibilities of selecting the most convenient solution among many such available solutions to ensure the tool feed motion, when designing a device for achieving an ultrasonic drilling process. At present, this selection could be achieved by means of an optimal selection method. Taking into consideration some functional requirements of the device, the method of analytic hierarchy process and the axiomatic design theory were used to solve some problems met in the design process.
\end{abstract}

\section{Introduction}

One of the manufacturing processes allowing the generation of the final part surfaces could be a process in which the material is removed from the workpiece in various ways. Over the years, distinct methods were identified and applied to remove the material from the workpiece. If the basic phenomena are considered, the machining methods applied in manufacturing processes could be grouped into two essential categories. Firstly there are machining methods based on the plastic deformation of the workpiece material by the tool up to the moment when a shearing phenomenon develops and a part of the workpiece material is removed as a chip; due to their first appearance and actual widespread use, these machining methods are called classical or conventional. Classical machining methods include cutting methods such as turning, milling, drilling, planing grinding, honing, etc.

On the other hand, there are situations when, due to the high hardness of the workpiece material or to the complex shapes of the part to be obtained, the conventional machining methods proved to be less convenient or really inapplicable. In order to remove or diminish the disadvantages specific to such situations, the researchers investigated the possibilities to bring more energy in the machining zone, so that either the classical machining methods could be applied in better conditions or new machining methods were proposed and afterward promoted. The technologies corresponding to this last group were called nonconventional or nontraditional machining methods. Nowadays, some relatively distinct methods are considered as belonging to the nonconventional machining methods; such methods are ultrasonic machining (USM), electrical discharge machining, electrochemical machining, chemical machining, plasma machining and ion machining, laser beam machining, electron beam machining, machining with moving liquid or gases, etc. The field of the nonconventional machining methods is not clearly delimited; in the last decades, other new machining methods were included in this field and, on

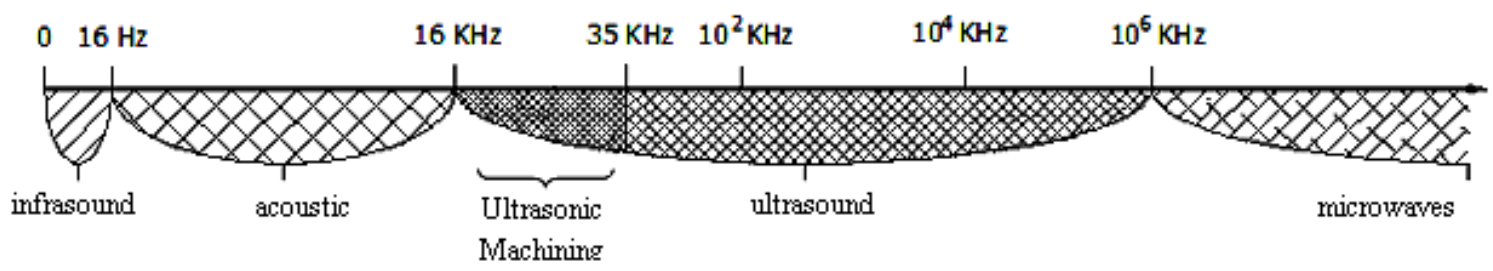

Fig. 1. Frequency domains of elastic mechanical oscillations.

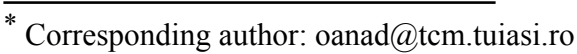




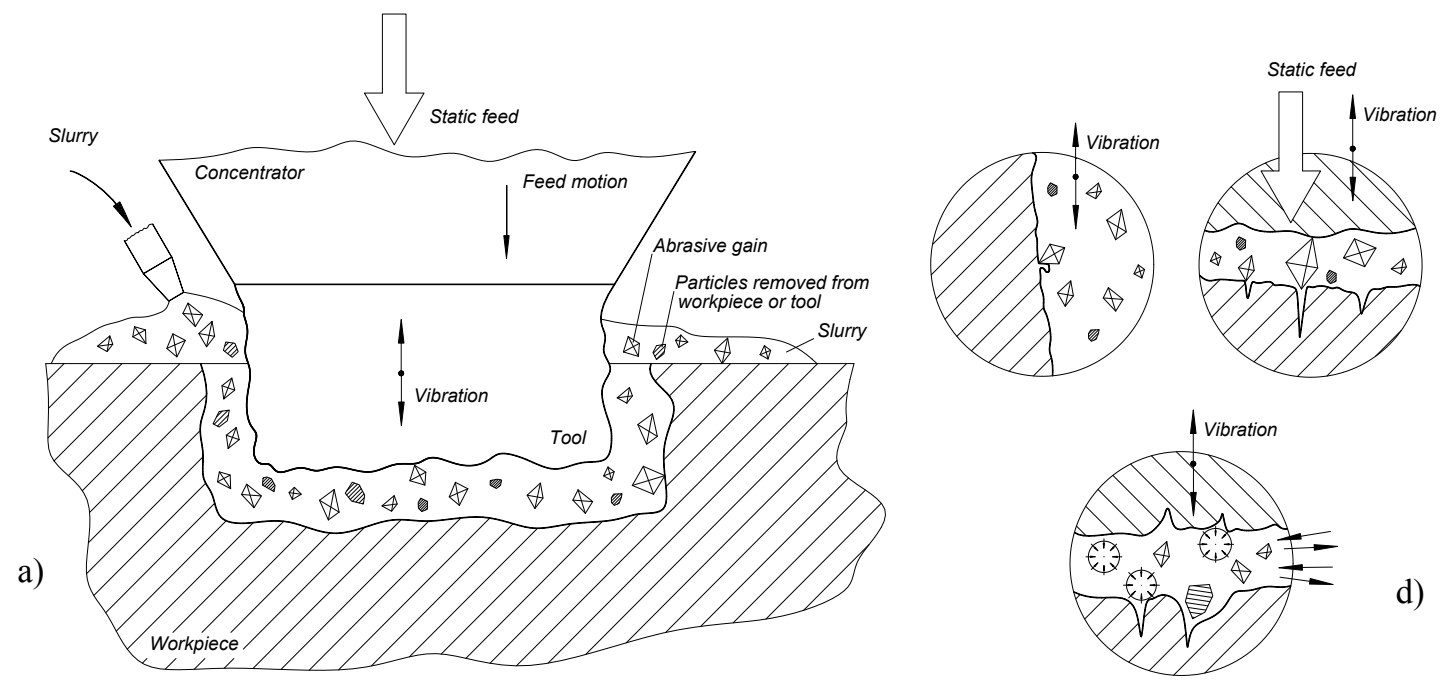

Fig. 2. Scheme of ultrasonic machining process $(a)$ and material removal processes by microchipping $(b)$, microcracking $(c)$ and cavitational phenomena $(d)$.

the other part, hybrid machining methods were proposed by combining either classical machining methods with nonconventional machining methods or just two or many nonconventional machining methods.

A group of nonconventional machining methods supposing the material removal from the workpiece are based on the use of ultrasounds called thus due to the use of vibration motions that have a frequency higher than the frequencies corresponding to the human audible field (Figure 1). The used vibration frequency is of about 19 $25 \mathrm{kHz}$ and the amplitude is of $10-50 \mu \mathrm{m}$.

One of the design methods initiated and developed in the last decades is the axiomatic design method. It is known that this design method essentially takes into consideration two axioms, namely the axiom needing the independence of the functional requirements and the axiom of minimum information, respectively [1]. Even the method was initially proposed as a method of designing mechanical equipment, manufacturing processes, and systems, at present the method was applied to solve a large variety of problems.

Over the years, the researchers tried to establish connections between the ultrasonic machining process or equipment and the axiomatic design method.

Thus, in a paper aiming to highlight the use of fuzzy axiomatic design principles in the selection of the nontraditional machining processes, Khandekar and Chakraborty took into consideration inclusively the ultrasonic machining as a machining technique applicable to materialize processes of micro-drilling in workpieces made of hardened tool steel [2]. They concluded that in such a case, the electrical discharge machining is an adequate machining process, followed by abrasive jet machining and ultrasonic machining.

In a book in which the problem of using axiomatic design in the fabrication of composite structure was approached, Lee and Suh referred inclusively to the ultrasonic machining [3]. They appreciated that within this machining method, the stress generated by a very short contact time between the tool and workpiece (10 to
$100 \mu \mathrm{s})$ is able to produce microchipping and erosion effects, but the method is limited to workpieces of size below $100 \mathrm{~mm}$, due to the difficulty of tool penetration in deeper cavities.

Mourão et al. developed an analysis of the way in which certain distinct non-conventional machining systems could be selected using the axiomatic design theory [4]. They analyzed inclusively the capability characteristics of the ultrasonic machining systems, when as selecting criteria the material removal rate, accuracy, surface roughness, damage depth, corner radii, capital cost, tooling and fixture cost, power requirement and tool consumption are considered.

The objective of the research presented in this paper was to identify and design constructive solutions for the investigation of the influence exerted by some factors corresponding to the ultrasonic abrasive cavitational machining on the values of the parameters of technological interests specific to such a nonconventional machining technique.

\section{Work principle in the case of ultrasonic machining}

Within the techniques able to materialize a process of material removal from the workpiece, there is a group which uses the vibration of a suspension of abrasive grains found in a liquid (frequently, water). Due to the phenomena developed in the work zone, this group constitutes the abrasive cavitational machining techniques.

There are distinct techniques able to exploit the abrasive cavitational processes; one may take into consideration the ultrasonic drilling, ultrasonic turning, ultrasonic cutting etc. Essentially, there is a tool which is pressed against the surface to be machined, in the presence of the abrasive slurry (Figure 2).

If the processes developed in the work zone are analyzed, one could notice: 
- a microchipping process, due to the vibration of the sharp and hard abrasive grains found in contact with the workpiece surface; in certain conditions, these abrasive grains could remove fine microchips from the workpiece superficial layer;

- a microcracking process developed essentially by the sharp and hard abrasive grains pressed on the workpiece surface layer; if the workpiece material is fragile enough, the grains could initiate a microcracking process. The extension and the connection of the microcracks may facilitate the gradual separation of small parts from the workpiece material;

- a microcavitation process, consisting in the breaking of the working fluid mass in small particles and their reunion under the action of the ultrasonic vibration. The liquid seems to boil, due to the virtual existence of a certain type of bubbles. The generation and the disappearance of the bubbles are accompanied by processes of increase and decrease of the local pressure, so that another factor able to generate microcracks may be signalized. As in the previous situation, the joining of the microcracks finally determines the material removal from the workpiece as small particles.

As a consequence of such phenomena developed in the work zone, small quantities of material are separated from both the workpiece and tool; if certain specific machining conditions are met, the material removal is more intense in the workpiece surface layer than in the tool active surface layer. To remove the particles detached from tool and workpiece and found in the work gap existing between the machined surface and the tool active surface, usually, a way of the abrasive slurry circulation is adopted. For example, one may take into consideration inclusively the process of pressure increase and decrease as a consequence of periodical approach and removal motions due to the ultrasonic vibrations.

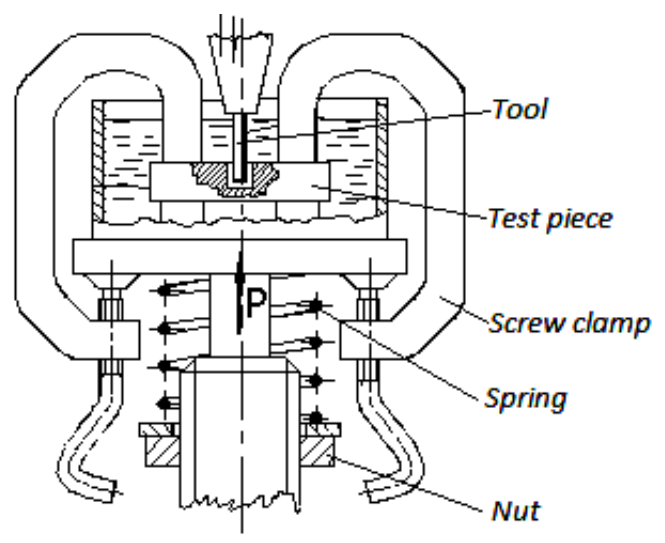

Fig. 3. Device for positioning and clamping the workpiece at ultrasonic machining based on the use of a spring.
In accordance with the general requests valid in the case of a machining technique, as a parameter of technological interest one may consider the material removal rate, the machining accuracy, the roughness of the machined surface, the tool wear etc.

There are some groups of ultrasonic process input factors able to exert influence on the parameter of technological interest valid for the ultrasonic machining:

a) Characteristics of vibration motion: amplitude, frequency, the variation of the amplitude in time etc.;

b) Chemical composition and physical properties of the workpiece material; generally, one appreciates that fragile materials have a better machinability by ultrasonic machining techniques;

c) Chemical composition and physical properties of the tool material; in this case, a certain tenacity of the tool material may increase the tool life;

d) The shape of the tool active surface and the trajectory to be met as a consequence of the relative work motions between tool and workpiece;

f) Characteristics of the working liquid found in the work gap and the chemical and physical properties of the abrasive grains. Thus, small-dimension grains are used in the case of the ultrasonic finishing processes and fine abrasive grains are used in the case of roughing ultrasonic processes when the material removal rate could be considered as an important parameter of technological interest;

g) The pressure exerted between the tool active surface and the workpiece surface to be machined. It is necessary that this pressure has a value between certain limits, to ensure a more convenient development of ultrasonic machining process and simultaneously an efficient of the worn abrasive particles from the work gap. If the pressure is too low, the intensity of the microcracking phenomenon is diminished, while a too high pressure could intensify a possible fracture process able to affect the integrity of the abrasive particles.

The above-mentioned processes specific to the ultrasonic machining highlighted the necessity of determining and applying a certain relative pressure between the tool and workpiece. It is possible that this pressure has specific values for distinct ultrasonic machining processes (distinct machining techniques, distinct dimensions, and shapes of the abrasive grains, distinct workpieces materials etc.). To better understand and apply the abrasive cavitational machining techniques, detailed knowledge concerning the pressure between tool and workpiece in the ultrasonic machining could be necessary; to investigate the possible influence exerted by the relative pressure on the values of the parameters of technological interest, the problem of designing a device able to offer a variable known pressure was stated.

The objective of the research presented in this paper was to use the axiomatic design in order to design and develop a device for investigation of the influence exerted by the pressure between the tool and workpiece in the abrasive cavitational ultrasonic machining. 
Table 1. $F R$ s and $D P \mathrm{~s}$ for the device for generating and changing the values of this machining relative pressure and clamping small dimensions test pieces.

\begin{tabular}{|c|c|c|c|c|c|c|c|}
\hline Line no. 1 & \multicolumn{2}{|c|}{ Design parameters } & \multirow{2}{*}{$\begin{array}{c}D P 1: \\
\text { Ultrasonic } \\
\text { machining } \\
\text { equipment } \\
4\end{array}$} & \multirow{2}{*}{$\begin{array}{l}D P 2: \\
\text { Ring } \\
\text { plate } \\
\\
5\end{array}$} & \multirow{2}{*}{\begin{tabular}{|c|}
\multicolumn{1}{|c|}{$D P 3:$} \\
Plastic \\
recipient \\
6
\end{tabular}} & \multirow{2}{*}{$\begin{array}{l}\text { DP4: } \\
\text { Screw } \\
\text { clamp } \\
\\
7\end{array}$} & \multirow{2}{*}{$\begin{array}{c}D P 5: \\
\text { Spring } \\
\text { and nut } \\
8\end{array}$} \\
\hline $\begin{array}{c}\text { Column } \\
\text { no. } 1\end{array}$ & 2 & 3 & & & & & \\
\hline 3 & $\begin{array}{l}\text { Functional requirement of } \\
\text { zero level }\end{array}$ & $\begin{array}{c}\text { Functional } \\
\text { requirements } \\
\text { of the first } \\
\text { level }\end{array}$ & \multicolumn{5}{|c|}{$\begin{array}{c}\text { Design parameters corresponding to each functional } \\
\text { requirement }\end{array}$} \\
\hline 4 & \multirow{6}{*}{$\begin{array}{l}\text { Design a device for generating } \\
\text { and changing the values of this } \\
\text { machining relative pressure and } \\
\text { clamping small dimensions test } \\
\text { pieces }\end{array}$} & $F R 1$ & $\mathrm{X}$ & & & & \\
\hline 5 & & $F R 2$ & & $\mathrm{X}$ & & & \\
\hline 6 & & FR3 & & & $\mathrm{X}$ & & \\
\hline 7 & & FR4 & & & & $\mathrm{X}$ & \\
\hline 8 & & FR5 & & & & & $\mathrm{X}$ \\
\hline 9 & & FR6 & & & & & $\mathrm{X}$ \\
\hline
\end{tabular}

FR2: Ensure components for positioning of the test piece and which allow the drilling of the test piece;

FR3: Ensure the immersion of the work zone

3 Functional requirements in the case of a device for the study of the
ultrasonic abrasive process

In accordance with the graphical representation from Figure 2, one could consider that to obtain better knowledge concerning the influence exerted by the relative pressure between the tool and workpiece in the ultrasonic process, an adequate device has to be imagined; within the axiomatic design method, this could be the main customer need.

In the laboratory for nonconventional machining technologies from the "Gheorghe Asachi" Technical University of Iași - Romania, there is some equipment for ultrasonic machining of small and medium dimension workpieces.

Initially, an older ultrasonic machine was taken into consideration; in such a case, the sonotrode could be vertically moved to ensure the initial contact between the tool and the test piece. The available machining equipment includes a threaded vertical bar, fixed at one end on the machine tool table, while at the other end, a circular massive block table could be placed on the threaded zone of the bar.

The functional requirement of zero order $(F R 0)$ could be: design a device adaptable on the ultrasonic machining equipment able to ensure possibilities of generating and changing the values of this machining relative pressure and clamping small-dimension test pieces.

If the analysis of the desired device is detailed, one could state the following functional requirements of second order:

FR1: Ensure general conditions valid in the case of ultrasonic machining (vibration movement with imposed values of the amplitude, frequency and amplitude change in time), a work movement along an established trajectory and positioning the tool over the workpiece; including the tool and test piece in the abrasive slurry;

FR4: Ensure possibilities of clamping the test piece in the recipient used for immersion of the tool and test piece in the abrasive slurry and, if possible, of simultaneous clamping of the recipient on the machine tool table;

FR5: Ensure a subsystem for materializing a variable relative pressure between thin test pieces and tool;

FR6: Ensure possibilities of achieving a relative rectilinear work motion between the test piece and tool.

\section{Design matrices in the case of two devices for study of abrasive ultrasonic machining}

The initial matrix including the functional requirements and design parameters corresponding to the above-mentioned functional requirements is presented in Table 1. One may notice that the solutions adopted for each functional requirement were the following:

$D P 1$ : existing equipment for ultrasonic machining;

$D P 2$ : ring plate;

$D P 3$ : transparent plastic recipient;

$D P 4$ : Screw clamp (2 such screw clamps);

$D P 5$ : Spring and nut placed on the threaded bar;

DP6: Spring and nut placed on the threaded bar.

The functional requirements and the adequate initial design parameters were included in the matrix represented by the content of Table 1. During the zigzagging activity, one noticed that there is the possibility to use two screw clamps both to clamp the thin test pieces in the plastic recipient and simultaneously the recipient on the threaded bar attached to the machine tool table. Examining the content of Table 1, one may notice that the use of the screw clamps for meeting two functional requirements generated an uncoupled matrix. To eliminate the uncoupled character of the matrix, a joining of the functional requirements no. 5 and 6 could be applied. 
Table 2. $F R \mathrm{~s}$ and $D P \mathrm{~s}$ in the case of the device for generating and changing the values of pressure and longer work strokes

\begin{tabular}{|c|c|c|c|c|c|c|c|c|c|c|c|c|c|}
\hline Line & & & & & & esigI & ram & $s$ of & tor & & & & \\
\hline 2 & $\begin{array}{c}\text { Functional } \\
\text { requirements }\end{array}$ & 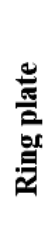 & 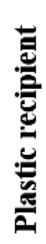 & 言 & 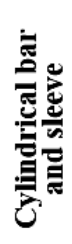 & 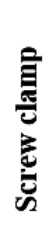 & $\frac{\text { है }}{2}$ & 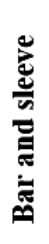 & 常 & 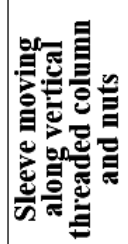 & 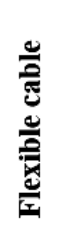 & 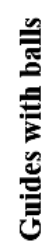 & 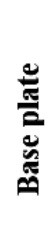 \\
\hline $\begin{array}{c}3 / \\
\text { Column } \\
\text { no.1 }\end{array}$ & 2 & 3 & 4 & 5 & 6 & 7 & 8 & 9 & 10 & 11 & 12 & 13 & 14 \\
\hline 4 & $\begin{array}{c}\text { Functional } \\
\text { requirements } \\
\text { of first order }\end{array}$ & & & poI & nce be & en $f$ & tion: & quil & ents & and desig & para & ters & \\
\hline 5 & $F R 1$ & $\mathrm{X}$ & & & & & & & & & & & \\
\hline 6 & $F R 2$ & & $\mathrm{X}$ & & & & & & & & & & \\
\hline 7 & FR3 & & & $\mathrm{X}$ & & & & & & & & & \\
\hline 8 & FR4 & & & & $\mathrm{X}$ & & & & & & & & \\
\hline 9 & FR5 & & & & & $\mathrm{X}$ & & & & & & & \\
\hline 10 & FR6 & & & & & & $\mathrm{X}$ & & & & & & \\
\hline 11 & FR7 & & & & & & & $\mathrm{X}$ & & & & & \\
\hline 12 & FR8 & & & & & & & & $\mathrm{X}$ & & & & \\
\hline 13 & FR9 & & & & & & & & & $\mathrm{X}$ & & & \\
\hline 14 & FR10 & & & & & & & & & & $\mathrm{X}$ & & \\
\hline 15 & FR11 & & & & & & & & & & & $\mathrm{X}$ & \\
\hline 16 & FR12 & & & & & & & & & & & & $\mathrm{X}$ \\
\hline
\end{tabular}

As a result of attempts to solve the functional requirements and adequate selection of the design parameter, finally, the solution presented in Figure 3 was developed [5]. One may remark that in our case, the screw clamps usually used to clamp two parts allowed a certain simplifying of the solution adopted and a creative solving of the stated problem. Rotating the nut that supports the spring, the elastic component is compressed and it is able to generate the necessary pressure between tool and test piece. Since the spring could be compressed by different vertical feeds of the nut, distinct values of the pressure could be obtained. However, the use of the nut and spring to simultaneously meet the functional requirements 5 and 6 generated a certain disadvantage; as the tool penetrated the test piece, the spring relaxes and the value of the pressure diminishes; for this reason, the device could be applied only in the case of low depths of ultrasonically machined holes, when the variation of the pressure could be neglected.

A second approaching of the same problem was necessary to remove or at least to diminish this disadvantage. The new objective was to find a solution able to ensure a constant pressure as the tool penetrates in the test piece.

The principle of interconnected vessels was mentioned during the discussion of persons interested in solving the new problem, but one remarked the difficulties possible to be generated by the necessity of sealing the joining type cylinder - piston, the last part is used both to support the subsystem for positioning and clamping the test piece and the changeable weights used to generate distinct values for the relative pressure

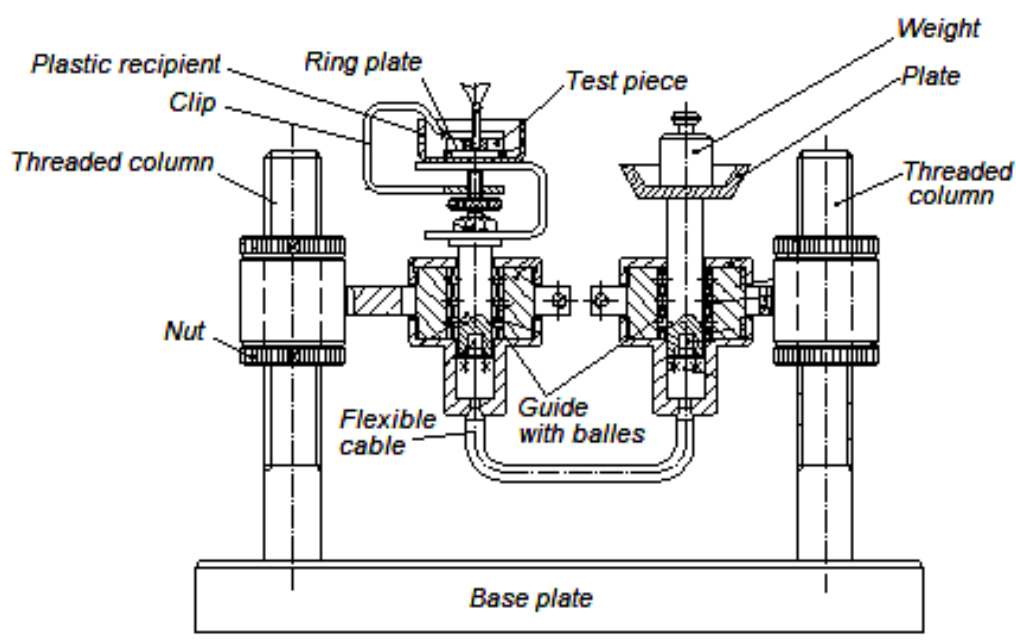

Fig. 4. Device for generating variable relative pressure at ultrasonic machining 
involved by the ultrasonic machining process. Somebody remarked a simple solution applied in the case of bicycles, when the brake force is transmitted from the handlebars to the break elements by means of a flexible cable; such a cable or a special flexible cable could also be used to transmit the variable force generated by distinct weights to the part able to support the recipient containing the test piece. Once this idea was outlined, the first principle of axiomatic design could be applied.

In this way, the functional requirement of zero order could have the aspect:

FR0: design a device that could be used in the case of ultrasonic machining, able to ensure the change of the value corresponding to the pressure developed between tool and test piece and also possibilities of achieving holes with a higher depth.

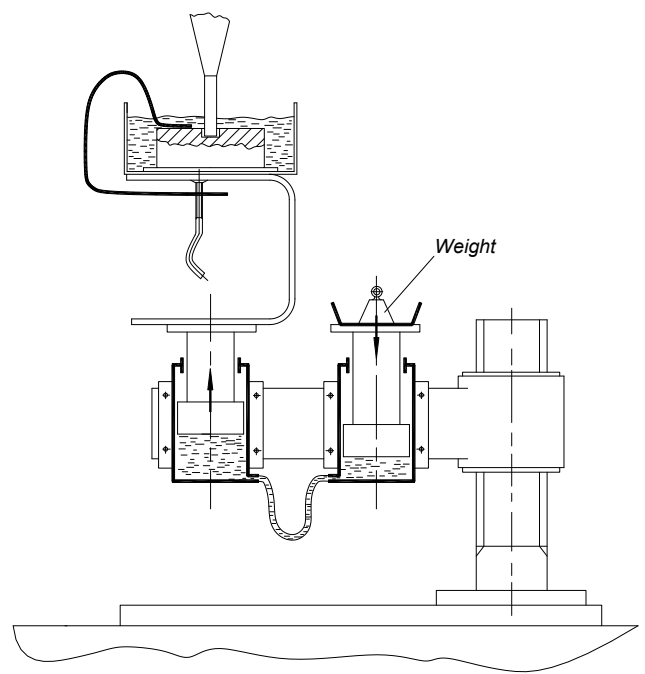

a

$\mathrm{c}$

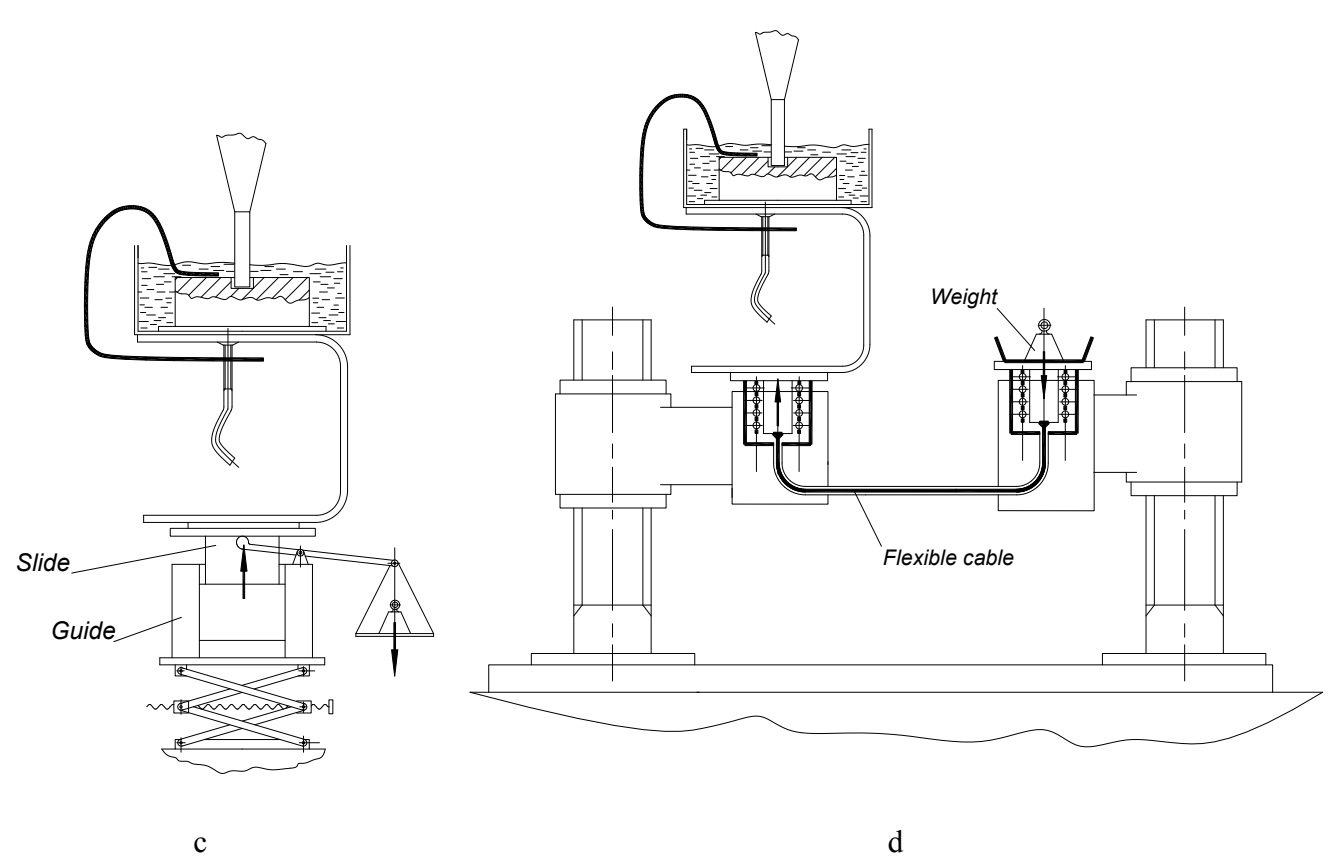

As functional requirements of the first order, one may consider:

$F R 1$ ensure: positioning and clamping the workpiece;

FR2: ensure a possibility of immersing the work zone, including the tool and test piece, in an abrasive slurry;

FR3: ensure a plate on which the possible recipient containing the abrasive slurry could be placed;

FR4: ensure a bar that could be moved in a sleeve to support the plate;

FR5: ensure positioning and clamping the subsystem supporting the test piece along a vertical direction, to contact the ultrasonic tool;

FR6: ensure a plate for placing distinct weights, able to generate a certain pressure between the ultrasonic tool and the test piece;

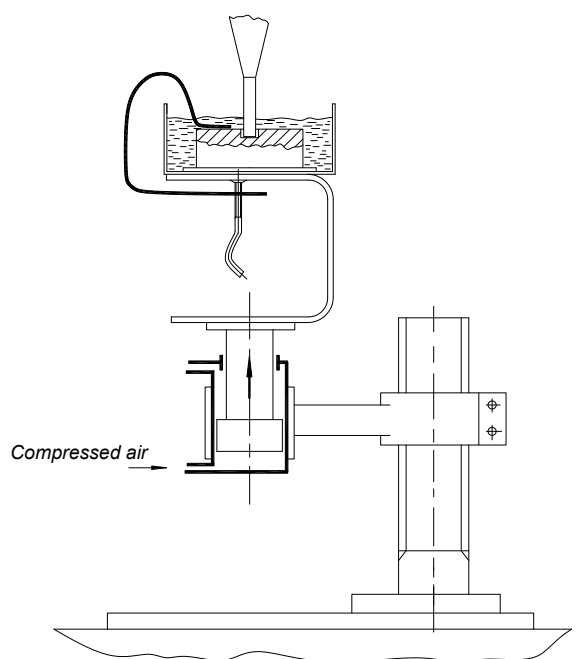

b

Fig. 5. Alternatives for the ultrasonic machining device: a - device based on the use of $A 1$ uses two hydraulic cylinders and a counterweight; $\mathrm{b}$ - alternative $A 2$, based on the use of a subsystem cylinder - piston and the compressed air; $\mathrm{c}$ - alternative $A 3$, that uses a mechanism inspired by the solution car jack type mechanism and a lever acted by a counterweight; $\mathrm{d}-$ alternative $A 4$, based on the use of two pistons connected by a flexible cable and a counterweight. 
FR7: ensure a bar that could be moved in a sleeve to support the plate with distinct weights;

FR8: ensure movement of the plate supporting the weights along a vertical direction, in order to generate the work motion and compensate the penetration of the ultrasonic tool into test piece;

FR9: ensure positioning and clamping the subsystem supporting the weights along a vertical direction;

FR10: ensure transmitting vertical movement of the subsystem supporting the weights along the vertical direction;

FR11: diminish the friction between the parts able to ensure the movement of subsystems supporting the test piece and distinct weights, respectively;

FR12: ensure a base piece on which the distinct subsystems could be positioned and fixed.

For each of the above-mentioned functional requirements, using a zigzagging investigation, design parameters $D P$ s were identified, analyzed and established. The obtained results were used to gradually elaborate the matrix included in Table 2 .

On the base of the considerations concerning the functional requirements and the selected constructive alternative for these requirements, the principle solution presented in Figure 4 was elaborated [6]. One may notice that the matrix corresponding to this version of the device is an uncoupled matrix.

During the elaboration of the solution, other functional requirements were highlighted (for example, one noticed that, probably, due to the vibration phenomenon, an unscrewing of screws and nuts could appear and adequate solving this problem will be considered before approaching the stage of manufacturing the device.

Table 3. Results of comparing the evaluation criteria two by two.

\begin{tabular}{|c|c|c|c|c|c|c|c|c|}
\hline Line & \multicolumn{8}{|c|}{ Criteria } \\
\hline 2 & \multicolumn{6}{|c|}{ Decision matrix } & \multirow[t]{2}{*}{ Priority } & \multirow[t]{2}{*}{ Rank } \\
\hline 3 & Criterion & $C 1$ & C2 & C3 & $C 4$ & $C 5$ & & \\
\hline $\begin{array}{c}\text { Line } \\
\text { no. } 4 \\
\text { Co- } \\
\text { lumn } \\
\text { no. } 1\end{array}$ & 2 & 3 & 4 & 5 & 6 & & 7 & 8 \\
\hline 5 & $C 1$ & 1 & 4.00 & 5.00 & 3.00 & 2.00 & $44.4 \%$ & 1 \\
\hline 6 & $C 2$ & 0.25 & 1 & 1.00 & 2.00 & 1.00 & $14.5 \%$ & 3 \\
\hline 7 & $C 3$ & 0.20 & 1.00 & 1 & 2.00 & 0.50 & $12.1 \%$ & 4 \\
\hline 8 & $C 4$ & 0.33 & 0.50 & 0.50 & 1 & 0.33 & $8.4 \%$ & 5 \\
\hline 9 & $C 5$ & 0.50 & 1.00 & 2.00 & 3.00 & 1 & $20.6 \%$ & 2 \\
\hline 10 & \multicolumn{4}{|c|}{$\begin{array}{l}\text { Number of comparisons: } \\
10\end{array}$} & \multicolumn{4}{|c|}{$\begin{array}{l}\text { Principal eigen value } \\
\lambda_{\max }=5,171\end{array}$} \\
\hline 11 & \multicolumn{4}{|c|}{$\begin{array}{l}\text { Consistency ratio } C R \\
\%=3.8\end{array}$} & \multicolumn{4}{|c|}{$\begin{array}{l}\text { Eigenvector solution: } 4 \\
\text { iterations, delta }=8.8 \mathrm{E}-10\end{array}$} \\
\hline
\end{tabular}

\section{Methods of optimal selection}

Essentially, the concept of optimization refers to a selection of one or many solutions appreciated as maximally convenient among many available solutions.

The optimization could be applied in many fields of the human activity. Over the years, the researchers searched and developed adequate methods for the mathematical solving of the optimization problems.

The current field of decision analysis includes a group of methods applicable to select a certain version when there are many available solutions. If the optimal solution is found using a single selection criterion, this situation corresponds to the monocriterial optimization, while when the necessity of simultaneous fulfilling of many criteria is stated, there is a problem of multicriterial optimization.

Some of the current methods of mono- or multicriterial optimization are: value analysis $-V A$, technique of matrix with two inputs, the technique of the imposed decision, the Technique for Order of Preference by Similarity to Ideal Solution (TOPSIS), analytic hierarchy process $(A H P)$, digraph-based approach, analytic network process $(A N P)$, data envelopment analysis $(D E A)$, preference ranking organization method for enrichment evaluation (PROMETHEE), geometrical analysis for interactive aid (GAIA), multi-objective optimization on the basis of ratio analysis (MOORA), Electre methods (in French, ELimination Et Choix Traduisent la REalité), multi-attribute utility theory $(M A U T)$, superiority and inferiority ranking method $(S I R)$ method, potentially all pairwise rankings of all alternatives (PAPRIKA) etc.

Some of the optimization methods are based on the comparison two by two of the versions previously identified.

Within the method of the matrix with two inputs, this comparison is made taking into consideration the global image of each alternative of problem-solving.

The method of imposed decision achieves initially the evaluation and the weighting of the criteria applicable to find the optimal solution and subsequently the alternatives are evaluated by means of each criterion. A final importance coefficient takes into consideration both the weighting of the criteria and the evaluation of each alternative by means of each evaluation criterion. When comparison of the criteria or of the alternatives is made, only three situations are considered and evaluated by marks: 1-0 when the first alternative is better appreciated, 0-1 when the second alternative is considered as more convenient, and $0.5-0.5$ when the two alternatives are considered as of equal importance.

In the case of the analytic hierarchy process (AHP), the comparisons are based on a more detailed analysis, highlighting of how many times an alternative is better by means of marks included between 2 and 9 (the mark 1 is attributed to the situations when the analyzed alternatives are considered as being of equal importance). 
Table 4. Results of comparison of the alternatives by means of each evaluation criterion.

\begin{tabular}{|c|c|c|c|c|c|c|c|}
\hline Line & \multicolumn{7}{|c|}{ Criterion $C 1$ : work pressure and motion } \\
\hline 2 & \multicolumn{5}{|c|}{ Decision matrix } & \multirow[t]{2}{*}{ Priority } & \multirow[t]{2}{*}{ Rank } \\
\hline 3 & Alternative & Al & $\overline{A 2}$ & $\mathbf{A 3}$ & $\boldsymbol{A 4}$ & & \\
\hline $\begin{array}{c}\text { Line } \\
4 \\
\text { Co- } \\
\text { lumn } \\
1\end{array}$ & 2 & 3 & 4 & 5 & 6 & 7 & \\
\hline 5 & Al & 1 & 3.00 & 1.00 & 1.00 & 27.9 & 2 \\
\hline 6 & 12 & 0.33 & 1 & 0.33 & 0.33 & 9.3 & 4 \\
\hline 7 & 13 & 1.00 & 3.00 & 1 & 4.00 & 42.3 & 1 \\
\hline 8 & 14 & 1.00 & 3.00 & 0.25 & 1 & 20.4 & 3 \\
\hline 9 & \multicolumn{3}{|c|}{$\begin{array}{l}\text { Number of } \\
\text { comparisons: } 6\end{array}$} & \multicolumn{4}{|c|}{$\begin{array}{l}\text { Principal eigen value } \\
\lambda_{\text {mar }}=4.29\end{array}$} \\
\hline 10 & \multicolumn{3}{|c|}{$\begin{array}{l}\text { Consistency ratio } C R \\
\%=9.1\end{array}$} & \multicolumn{4}{|c|}{$\begin{array}{l}\text { Eigenvector solution: } 5 \\
\text { iterations, delta=8.7E-8 }\end{array}$} \\
\hline 11 & \multicolumn{7}{|c|}{ Criterion C2: workpiece positioning } \\
\hline 12 & \multicolumn{5}{|c|}{ Decision matrix } & Priority & Rank \\
\hline 13 & Alternative & Al & $\overline{A 2}$ & $\mathbf{A B}$ & $\boldsymbol{A 4}$ & & \\
\hline 14 & $\overline{11}$ & 1 & 1.00 & 0.33 & 2.00 & 20.1 & 3 \\
\hline 15 & 12 & 1.00 & 1 & 0.50 & 3.00 & 24.8 & 2 \\
\hline 16 & 13 & 3.00 & 2.00 & 1 & 2.00 & 42.5 & 1 \\
\hline 17 & 14 & 0.50 & 0.33 & 0.50 & 1 & 12.5 & 4 \\
\hline 18 & \multicolumn{3}{|c|}{$\begin{array}{l}\text { Number of } \\
\text { comparisons: } 6\end{array}$} & \multicolumn{4}{|c|}{$\begin{array}{l}\text { Principal eigen value } \\
\lambda_{\text {mar }}=4.175\end{array}$} \\
\hline 19 & \multicolumn{3}{|c|}{$\begin{array}{l}\text { Consistency ratio CR } \\
\%=6.4\end{array}$} & \multicolumn{4}{|c|}{$\begin{array}{l}\text { Eigenvector solution: } 5 \\
\text { iterations, deltas }=4.0 \mathrm{E}-8\end{array}$} \\
\hline 20 & \multicolumn{7}{|c|}{ Criterion C3: low friction } \\
\hline 21 & \multicolumn{5}{|c|}{ Decision matrix } & Priority & Rank \\
\hline 22 & Alternative & Al & $\overrightarrow{A 2}$ & $\mathbf{A 3}$ & $A 4$ & & \\
\hline 23 & Al & 1 & 0.50 & 0.50 & 0.25 & 10.8 & 4 \\
\hline 24 & 12 & 2.00 & 1 & 0.50 & 0.33 & 16.4 & 3 \\
\hline 25 & 13 & 2.00 & 2.00 & 1 & 0.50 & 25.6 & 2 \\
\hline 26 & 14 & 4.00 & 3.00 & 2.00 & 1 & 47.2 & 1 \\
\hline 27 & \multicolumn{3}{|c|}{$\begin{array}{l}\text { Number of } \\
\text { comparisons: } 6\end{array}$} & \multicolumn{4}{|c|}{$\begin{array}{l}\text { Principal eigen value } \\
\lambda_{\text {mar }}=4.046\end{array}$} \\
\hline 28 & \multicolumn{3}{|c|}{$\begin{array}{l}\text { Consistency ratio } \mathrm{CR} \\
\%=1.7\end{array}$} & \multicolumn{4}{|c|}{$\begin{array}{l}\text { Eigenvector solution: } 4 \\
\text { iterations, delta }=1.8 \mathrm{E}-9\end{array}$} \\
\hline 29 & \multicolumn{7}{|c|}{ Criterion $C 4$ : constructive simplicity } \\
\hline 30 & \multicolumn{5}{|c|}{ Decision matrix } & \begin{tabular}{|l|l} 
Priority \\
\end{tabular} & Rank \\
\hline 31 & Alternative & Al & $\overline{A 2}$ & $\overline{A 3}$ & $\overline{A 4}$ & & \\
\hline 32 & Al & 1 & 0.33 & 0.50 & 0.50 & 12.0 & 4 \\
\hline 33 & 12 & 3.00 & 1 & 0.50 & 3.00 & 32.8 & 2 \\
\hline 34 & 13 & 2.00 & 2.00 & 1 & 2.00 & 38.3 & 1 \\
\hline 35 & 14 & 2.00 & 0.33 & 0.50 & 1 & 16.8 & 3 \\
\hline 36 & $\begin{array}{l}\text { Number of } \\
\text { comparisons: }\end{array}$ & & & $\begin{array}{l}\text { Princ } \\
\lambda_{\operatorname{mar}}=\end{array}$ & $\begin{array}{l}\text { ipal ei } \\
4.046\end{array}$ & igen value & \\
\hline 37 & $\begin{array}{l}\text { Conaistency r } \\
\%=1.7\end{array}$ & ratio $C$ & & $\begin{array}{l}\text { Eigen } \\
\text { iterati }\end{array}$ & $\begin{array}{l}\text { ivecto } \\
\text { ions, }\end{array}$ & $\begin{array}{l}\text { is solution: } \\
\text { delta=l.sE- }\end{array}$ & \\
\hline 38 & & iterion & $\mathrm{ACS}_{\mathrm{C}}$ & $\operatorname{mann}$ & factm & rability & \\
\hline 39 & & cision & matri & & & Priority & Rank \\
\hline 40 & Alternative & Al & $\overline{A 2}$ & A3 & $\overline{A 4}$ & $\%$ & \\
\hline 41 & Al & 1 & 0.33 & 0.50 & 1.00 & $13.9 \%$ & 4 \\
\hline 42 & 12 & 3.00 & 1 & 2.00 & 2.00 & $41.9 \%$ & 1 \\
\hline 43 & 13 & 2.00 & 0.50 & 1 & 3.00 & $29.7 \%$ & 2 \\
\hline 44 & 14 & 1.00 & 0.50 & 0.33 & 1 & $14.4 \%$ & 3 \\
\hline 45 & $\begin{array}{l}\text { Number of } \\
\text { comparisons: }\end{array}$ & & & $\begin{array}{l}P_{\text {rinc }} \\
\lambda_{\text {mar }}=\end{array}$ & $\begin{array}{l}\text { ipal ei } \\
4.046\end{array}$ & en value & \\
\hline 46 & $\begin{array}{l}\text { Conaistency r } \\
\%=1.7\end{array}$ & ratio $C$ & & $\begin{array}{l}\text { Eigen } \\
\text { iterati }\end{array}$ & $\begin{array}{l}\text { ivecto } \\
\text { ions, }\end{array}$ & $\begin{array}{l}\text { I solution: } \\
\text { delta=l.sE- }\end{array}$ & \\
\hline
\end{tabular}

\section{Use of AHP method}

As above mentioned, the AHP is a fine selection method, since there is a large scale of evaluation when comparing the alternatives two by two. The method was proposed by Thomas L. Saaty, architect and professor at the University of Pittsburg.

Some details concerning the stages corresponding to the AHP method used in the case of a device for evaluating the universal lathe university were presented in [7]. In this paper section, a more synthetic presentation of applying the $A H P$ method in the case of selecting a device for ultrasonic machining will be made.

As above-mentioned, the problem was to identify a solution for a device for clamping the workpiece on an ultrasonic machining equipment, when a hole of small diameter and length must be obtained. The available ultrasonic machine ensures only the vibration of the ultrasonic tool, so that the work motion and pressure must be achieved by the desired device. In fact, there is a possibility of achieving the work pressure and motion manually acting on a hand wheel.

One supposes that as a result of applying the axiomatic design principles or other methods for the creativity stimulation to find distinct solutions for a constructive problem four engineers individually established the alternatives presented in Figure 5:

- The alternative $A 1$ uses two hydraulic cylinders by which the pressure generated by the counterweights is transmitted to the device subassembly intended to press the workpiece on the active surface of the vibrating tool; - The alternative $A 2$ uses the compressed air to move and press the workpiece against the active surface of the vibrating tool;

- The alternative $A 3$ uses a mechanism inspired by the solution of a car jack to ensure the positioning coarse of the workpiece and a piston moved in a cylinder as a consequence of acting a lever by means of a counterweight;

- The alternative $A 4$ is based on the use of two pistons connected by a flexible cable and whose motions are guided by means of rollers sleeves. The work motion and pressure are ensured also by means of counterweights.

These solutions could be found, for example, by using the method of ideas diagram [8].

If in the case of the alternatives $A 1$ and $A 2$, a threaded column - nut type subsystem is used for positioning course of the workpiece, in the case of the alternative $A 4$ two such subsystems are necessary. A distinct solution was proposed in the case of the alternative $A 3$, based on the use of subsystem using the quadrilateral mechanism and a screw-nut mechanism, respectively.

In applying the $A H P$ method, five evaluation criteria were used: $C 1$ - the way of ensuring the work motion and pressure; $C 2$ - the way of achieving the workpiece positioning; $\mathrm{C} 3$ - the necessity of ensuring as possible a low friction for the moving components of the device; $C 4$ - the constructive simplicity; $C 5$ - the possibilities of manufacturing the device components using only machining equipment available in the mechanical workshop. 
Table 5. Determination of the general composite weight.

\begin{tabular}{|c|c|c|c|c|c|c|c|}
\hline \multirow{3}{*}{$\begin{array}{c}\text { Criterion } \\
\text { weight }\end{array}$} & \multicolumn{5}{|c|}{ Criterion } & \multirow{3}{*}{$\begin{array}{c}\text { Gene- } \\
\text { ral } \\
\text { com- } \\
\text { posite } \\
\text { weight } \\
\%\end{array}$} & \multirow[t]{3}{*}{ Rank } \\
\hline & C1 & $\mathrm{C2}$ & C3 & $\mathrm{C4}$ & $\mathrm{C5}$ & & \\
\hline & $\begin{array}{c}44.4 \\
\%\end{array}$ & $\begin{array}{c}14.5 \\
\%\end{array}$ & $\begin{array}{c}12.1 \\
\%\end{array}$ & $\begin{array}{l}8.4 \\
\%\end{array}$ & $\begin{array}{c}20.6 \\
\%\end{array}$ & & \\
\hline $\begin{array}{c}\text { Column } \\
\text { no. } 1\end{array}$ & 2 & 3 & 4 & 5 & 6 & 7 & 8 \\
\hline A1 & 27.9 & 20.1 & 10.8 & 12.0 & 13.9 & 20.48 & 4 \\
\hline $\mathrm{A} 2$ & 9.3 & 24.8 & 16.4 & 32.8 & 41.9 & 21.09 & 2 \\
\hline A3 & 42.3 & 42.5 & 25.6 & 38.3 & 29.7 & 37.37 & 1 \\
\hline A4 & 20.4 & 12.5 & 47.2 & 16.8 & 14.4 & 20.95 & 3 \\
\hline
\end{tabular}

The software proposed in [9] was used to solve the problems corresponding to distinct stages of applying the AHP method when selecting the more convenient alternative for the device necessary in the ultrasonic drilling. A synthesis of the calculus developed in these stages is shown in tables 3, 4 and 5 .

The content of table 3 highlights the results of comparing the evaluation criteria, in accordance with the principle of AHP and using an adequate software [9]. In table 2, other information obtained as a consequence of applying the AHP method was also included (number of comparisons, principal eigenvalue, consistency ratio, eigenvector solution).

The evaluation of each alternative by means of each criterion is presented in table 2. Thus, in the lines 5-8, the alternatives were evaluated by means of the criterion of the way of obtaining the work pressure and motion, in the lines $14-17$ - by means of the criterion of the workpiece positioning, in the lines $23-26$ - by means of the criterion of ensuring a low value for the friction coefficient, in the lines 32-35 - by means of the criterion of the constructive simplicity and in the lines 41-44 - by means of the criterion of manufacturability. In this way, for each alternative, a certain priority value was determined by considering a certain criterion.

The information synthetized in table 4 was used to calculate the so-called general composite weight for each alternative but considering the priority values previously determined and highlighted in table 4 . The results thus obtained were included in table 5 .

The priority size of each alternative was determined to take into consideration the weights of the criteria and of the alternatives by means of each criterion:

$$
\begin{aligned}
& \mathrm{A} 1=(44.60 \cdot 27.90+14.50 \cdot 20.10+12.10 \cdot 10.80+ \\
& 20.60 \cdot 13.90) / 100=20.48 \%
\end{aligned}
$$

$$
\begin{aligned}
& \mathrm{A} 2=(44.40 \cdot 9.30+14.50 \cdot 24.80+12.10 \cdot 16.40+ \\
& 8.40 \cdot 32.80+20.60 \cdot 41.90) / 100=21.09 \%
\end{aligned}
$$

$$
\mathrm{A} 3=(44.90 \cdot 42.30+14.50 \cdot 42.50+12.10 \cdot 25.60+
$$$$
8.40 \cdot 38.30+20.60 \cdot 29.70) / 100=32.37 \%
$$

$\mathrm{A} 4=(44.60 \cdot 20.40+14.50 \cdot 12.50+12.10 \cdot 47.20+$ $8.40 \cdot 16.80+20.60 \cdot 14.40) / 100=20.95$

On the base of the above-mentioned weights and the alternatives ranks included in the column no.7 from table 5 , one could decide that the most convenient alternative when all the distinct evaluation criteria are considered is the alternative $A 3$ that has the maximum general composite weight.

\section{Conclusions}

One of nonconventional machining techniques that may be used to achieve a hole with distinct transversal sections in difficult-to-cut materials could be the ultrasonic machining.

The ultrasonic machining is a machining method that has a version in which an abrasive slurry is affected by an ultrasonic vibration and the abrasive grains are pressed by the ultrasonic tool against the workpiece surface to be machined. In this way, a gradually material removal from workpiece contributes to the generation of a certain cavity. To investigate some aspects concerning such a non-conventional machining technique, the problem of designing a device able to ensure the changing of the pressure developed between the ultrasonic tool and test pieces was formulated. The analysis of the accessible work conditions by means of the first principle of axiomatic design facilitated initially the elaboration of a device able to ensure the change of the values of the pressure by means of a spring and simultaneously a work movement necessary to achieve a small depth hole. Due to the fact that as the ultrasonic tool penetrates the test piece the spring relaxes and the pressure could decrease up to less convenient values, the analysis was continued by considering a new version of the device, in which distinct weights generate the pressure by means of a flexible cable. In cases of both versions of devices, the elaboration of design matrix highlighted problems whose solving could ensure a better functioning of the devices and innovative ways of identifying and finding solutions for the approached problem. Even in the last case of the device for ultrasonic machining, there was the opinion that new versions of the device could be identified. Thus, one considered that using the axiomatic design or other methods for the stimulation of the technical creativity, four relatively distinct solutions were found. The stages of applying the analytic hierarchy method were used to finally detach another possible convenient solution. In the future, there is the intention to continue the investigation to see if applying other optimization methods, other device versions could be considered as optimal alternatives.

\section{References}

1. N. P. Suh, The Principles of Design (Oxford University Press, New York, 1990)

2. A. V. Khandekar, S. Chakraborty, Int J Adv Manuf Technol 83, 529 (2016)

3. D. G. Lee, N. P. Suh, Axiomatic Design and Fabrication of Composite Structures: Applications in Robots, Machine Tool, and Automobiles (Oxford University Press, Oxford, 2006) 
4. A. Mourão, G. Neştian, L. Slătineanu, A. M. Gonçalves-Coelho, Nonconventional Technologies Review 4, 50 (2007)

5. L. Apetrei, L. Slătineanu, L., A. Munteanu, O. Dodun, Patent Romania no. 122529 B1 (2006)

6. L. Slătineanu, O. Dodun-Des-Perrieres, M. Coteață, D. Uliuliuc, Patent Romania no. RO125894-A2 (2009)

7. L. Slătineanu, O. Dodun, M. Coteață, V. Dulgheru, P. Dușa, F. Banciu, I. Beșliu, ICAD 2017, MATEC Web of Conferences 127, 01019 (2017)

8. L. Slătineanu, M. Coteaţă, O. Dodun, A. Toca, Proceedings of the Fifth International Conference on Axiomatic Design (ICAD 2009), The New University of Lisbon, 2009, 79-84

9. K.D. Gospel, http://bpmsg.com/academic/ahp _catchup (2011), accessed: 5.05.2017 